\title{
KARAKTERISTIK CEBAKAN BAUKSIT LATERIT \\ DI DAERAH SEPILUK - SENANING, KABUPATEN SINTANG, KALIMANTAN BARAT
}

\author{
Oleh: \\ Eko Yoan Toreno dan Moe'tamar \\ Pusat Sumber Daya Geologi \\ Jl. Soekarno Hatta No. 444 Bandung
}

\begin{abstract}
SARI
Keberadaan bauksit laterit di daerah Sepiluk-Senaning, Kabupaten Sintang, Kalimantan Barat terbentuk pada kemiringan lereng $10^{\circ} \mathrm{s} . \mathrm{d}$. $14^{\circ}$. Batuan asal yang terdapat di daerah ini adalah batuan gunungapi pra-Tersier dengan jenis fonolit kaya akan kandungan unsur aluminium dengan mineral gibsit, felspar dan cliachit yang mudah larut kemudian mengalami proses laterisasi. Penyelidikan bauksit didaerah ini dilakukan dengan channel sampling pada sumur uji dengan ketebalan rata-rata bauksit laterit sebesar 2,6 m dan pengambilan conto sebanyak 39 . Hasil korelasi antara penampang sumur uji, memperlihatkan penyebaran bauksit lateritmenipis ke arah tenggara - baratlaut.
\end{abstract}

Berdasarkan hasil analisis kimia terhadap conto laterit diperoleh kadar rata-rata $52,64 \% \mathrm{Al}_{2} \mathrm{O}_{3}$; $3,60 \% \mathrm{SiO}_{2} ; 9,83 \% \mathrm{Fe}_{2} \mathrm{O}_{3}$ dan $1,34 \% \mathrm{TiO}_{2}$ dengan faktor konkresi 0,58 \%.

Kata kunci :bauksit, laterit, Sepiluk-Senaning, gibsit, felspar, cliachit

\begin{abstract}
The occurrence of lateritic bauxite deposits in the Sepiluk-Senaningarea, Sintang, West Kalimantanwas formed on the $10^{\circ}$ to $14^{\circ}$ slope. The source rock is Pre-Tertiary alumine rich phonolite with soluble minerals such as gibbsite,feldspar and cliachit then undertake lateritic proceses. Investigation was carried out by channel sampling in the test pitto collect 39 samples within average depth of $2.6 \mathrm{~m}$. Correlation among test pit cross sections showing the distribution of lateritic bauxite become thinner toward southeast - northwest.
\end{abstract}

Based on the chemical analysis of samples, the average grade of several substance are $52.64 \%$ $\mathrm{Al}_{2} \mathrm{O}_{3} ; 3.60 \% \mathrm{SiO}_{2} ; 9.83 \% \mathrm{Fe}_{2} \mathrm{O}_{3}$ and $1.34 \% \mathrm{TiO}_{2}$ with concretion factor of $0.58 \%$.

Keywords : bauxite, lateritic, Sepiluk-Senaning, gibbsite, feldspar, cliachit

\section{PENDAHULUAN}

Bauksit laterit merupakan suatu lapisan konkresi yang kaya aluminium dan besi, berwarna kemerahan - kecoklatan akibat terkontaminasi oleh oksida besi, berporidan terdapat di daerah tropis - subtropis. Bauksit relatif sangat lunak (1-3 Mohs), ringan (berat jenis 2,3-2,7 $\mathrm{gr} / \mathrm{cm}^{3}$ ) dengan rumus kimia $\mathrm{Al}_{2} \mathrm{O}_{3} \cdot 2 \mathrm{H}_{2} \mathrm{O}$ bersistem oktahedral, termasuk dalam kelompok aluminium hidroksida seperti gibsit $\left(\mathrm{Al}(\mathrm{OH})_{3}\right)$, boehmit ( $\gamma$ $\mathrm{AlO}(\mathrm{OH})$ )dan diaspor $(\alpha-\mathrm{AlO}(\mathrm{OH})$ ).

Bauksit dapat bersumber dari batuan primer (hidrotermal) maupun dari batuan sekunder (pelapukan). Keterdapatannya di permukaan bumi secara luas berasal dari batuan sekunder hasil proses pelapukan yang cukup kuat dan pelindian. Umumnya bauksit berasal dari syenit, lempung/serpih 
yang mengalami pelapukan dengan larutnya unsur $\mathrm{Na}, \mathrm{K}, \mathrm{Mg}$ dan $\mathrm{Ca}$ menjadi residu hidroksida alumina $\left(\mathrm{Al}(\mathrm{OH})_{3}\right)$ dan mengeras membentuk bauksit melalui proses dehidrasi. Sedangkan menurut Eggleton, (2001) Laterite adalah bagian atas dari suatu horison tanah yang kaya dengan oksida besi dan miskin silika sebagai hasil dari pelapukan intensif pada regolit.

Daerah penyelidikan merupakan daerah perbatasan Kalimantan Barat (Indonesia) dengan Serawak (Malaysia) yang secara administratif termasuk wilayah Kecamatan Ketungau Hulu, Kabupaten Sintang, Provinsi Kalimantan Barat (Gambar 1).

Di Kalimantan Barat, bauksit laterit terdapat pada jalur penyebaran dengan panjang $300 \mathrm{Km}$ dan lebar $50-100 \mathrm{Km}$ (Zona Laterit), yang membujur arah baratlaut - tenggara dari Kabupaten Ketapang, Sanggau, Landak, Kubu Raya, Pontianak, Bengkayang sampai Kota Singkawang (Alcomin,1974).

Geologi morfologi daerah penyelidikan terdiri dari satuan morfologi perbukitan terjal, diperkirakan mencakup sekitar $30 \%$ luas daerah penyelidikan tersebar di daerah bagian timur, utara dan sebagian di bagian tengah dengan kemiringan lereng $>25^{\circ}$, ketinggian berkisar 150-1.150m dpl. Umumnya satuan morfologi ini ditempati oleh satuan batupasir kuarsa Formasi Tutop dan batuan intrusi Sintang berupa andesit, diorit dan granodiorit berumur Pra-Tersier (Heryanto dkk, 1993). Selain itu terdapat satuan morfologi perbukitan bergelombang diperkirakan mencakup sekitar $70 \%$ luas daerah penyelidikan, merupakan daerah perbukitan dan lembah-lembah sungai dengan lereng landai - sedang, kemiringan lereng $<25^{\circ}$, yang banyak dimanfaatkan untuk lahan perkebunan sawit, karet dan akasia. Satuan morfologi ini ditempati oleh satuan perselingan batupasir halus dan batulempung, lensa batubara (Formasi Ketungau) dan satuan batupasir sisipan batulanau dan batulempung (Formasi Kantu).

Penyebaran batuan sedimen sangat luas, hampir menempati seluruh daerah penyelidikan, terletak tidak selaras menutupi batuan intrusi. Batuan yang tersingkap di utara daerah penyelidikan terdiri dari batupasir halus-sedang, berwarna putih keabu-abuan sampai kemerahan, berlapis baik dengan struktur sedimen perlapisan sejajar dan silangsiur, pada beberapa tempat

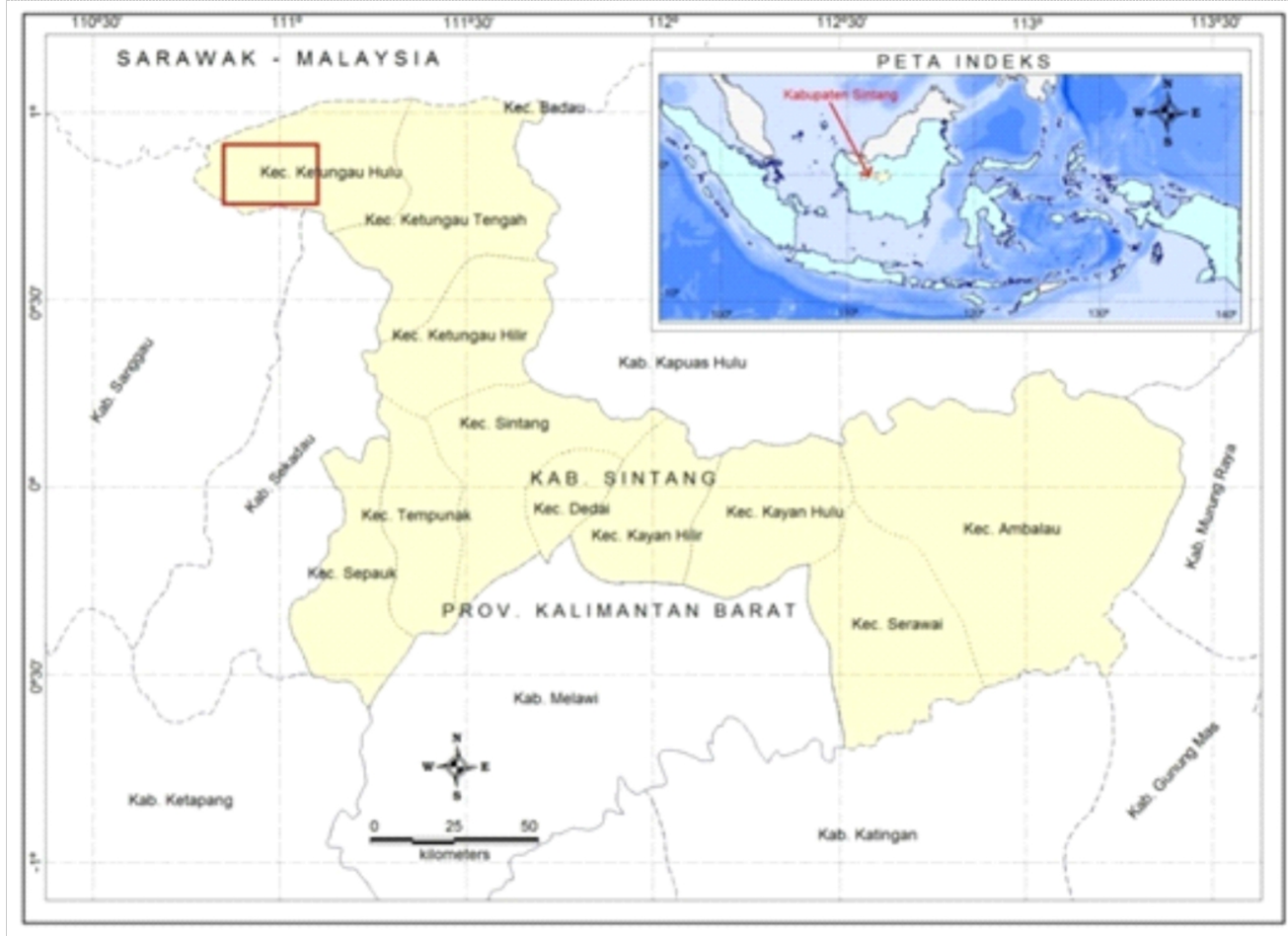

Gambar 1. Peta administrasi dan lokasi daerah penyelidikan 
nampak terdapat struktur graded bedding terutama pada sisipan batupasir berbutir kasar sampai konglomeratan dengan fragmen membulat dari mineral kuarsa dengan diameter hingga $1 \mathrm{~cm}$, jurus dan kemiringan $\mathrm{N} 175^{\circ} \mathrm{E} / 14^{\circ}$. Batupasir tersebut berselang-seling dengan batulempung dan batulanau (Gambar 2A), umumnya bersifat lunak hingga getas, berwarna abu-abu sampai abu-abu kehitaman, setempat berlapis baik dengan struktur sedimen perlapisan sejajar, kadang-kadang mengandung lapisan batubara yang sebagian sangat tipis hingga berbentuk lensa-lensa atau fragmen-fragmen batubara hasil transportasi (Gambar 2B). Hasil pengukuran pada lapisan batulempung menunjukkan jurus dan kemiringan $\mathrm{N} 240^{\circ} \mathrm{E} / 10^{\circ}$. Dari analisis petrografi, batupasir didaerah penyelidikan termasuk dalam klasifikasi batupasir litik terbreksikan (Litharenites), menurut Heryanto dkk, 1993 satuan batuan ini termasuk kedalam Formasi Kantu dengan kisaran umur Eosen.
Andesit dan batuan terubah granitik hingga granodiorit, diorit mengandung kuarsa, menempati bagian tengah daerah penyelidikan (Gambar 2C). Pada bagian permukaan dijumpai lapisan tipis oksida besi berupa limonit terisi pasir dan lempung (Gambar 2D), diduga berasal dari batuan asal dan terbentuk karena pelapukan dengan sebaran tanah laterit seluas $449.300 \mathrm{~m}^{2}$ (Gambar 3).

Struktur geologi di daerah penyelidikan terdiri dari sesar, pelipatan dan rekahan. Sesar berarah tenggara - baratlaut, ke barat umumnya agak sejajar dengan batas formasi. Kelompok sesar yang berarah timur - timurlaut memotong menyilang batas formasi tersebut. Sesar-sesar yang terdapat di daerah ini pada umumnya berupa sesar normal. Terdapat dua sesar utama yang mengontrol perkembangan struktur daerah tersebut. Secara umum struktur sinklin dan antiklin ditemukan pada batuan sedimen di bagian utara daerah penyelidikan.

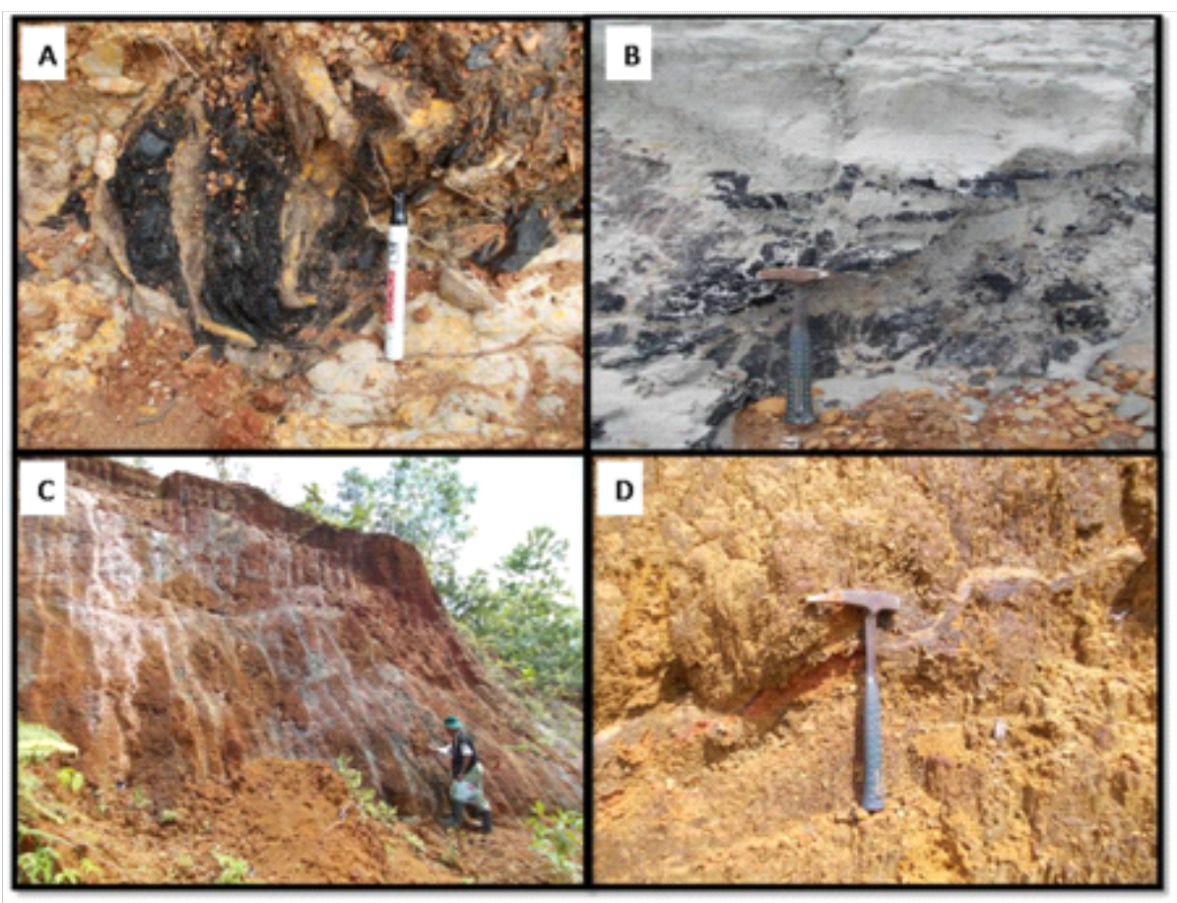

Gambar 2. A) Struktursilang siur batupasir dengan batulempung, terlihat fragmen batubara rapuh

B) Batupasir berselang - seling dengan batulempung dan batulanau dengan lensa batubara

C) Foto singkapan granit, andesit

D) Lapisan tipis oksida besi terisi lempung 


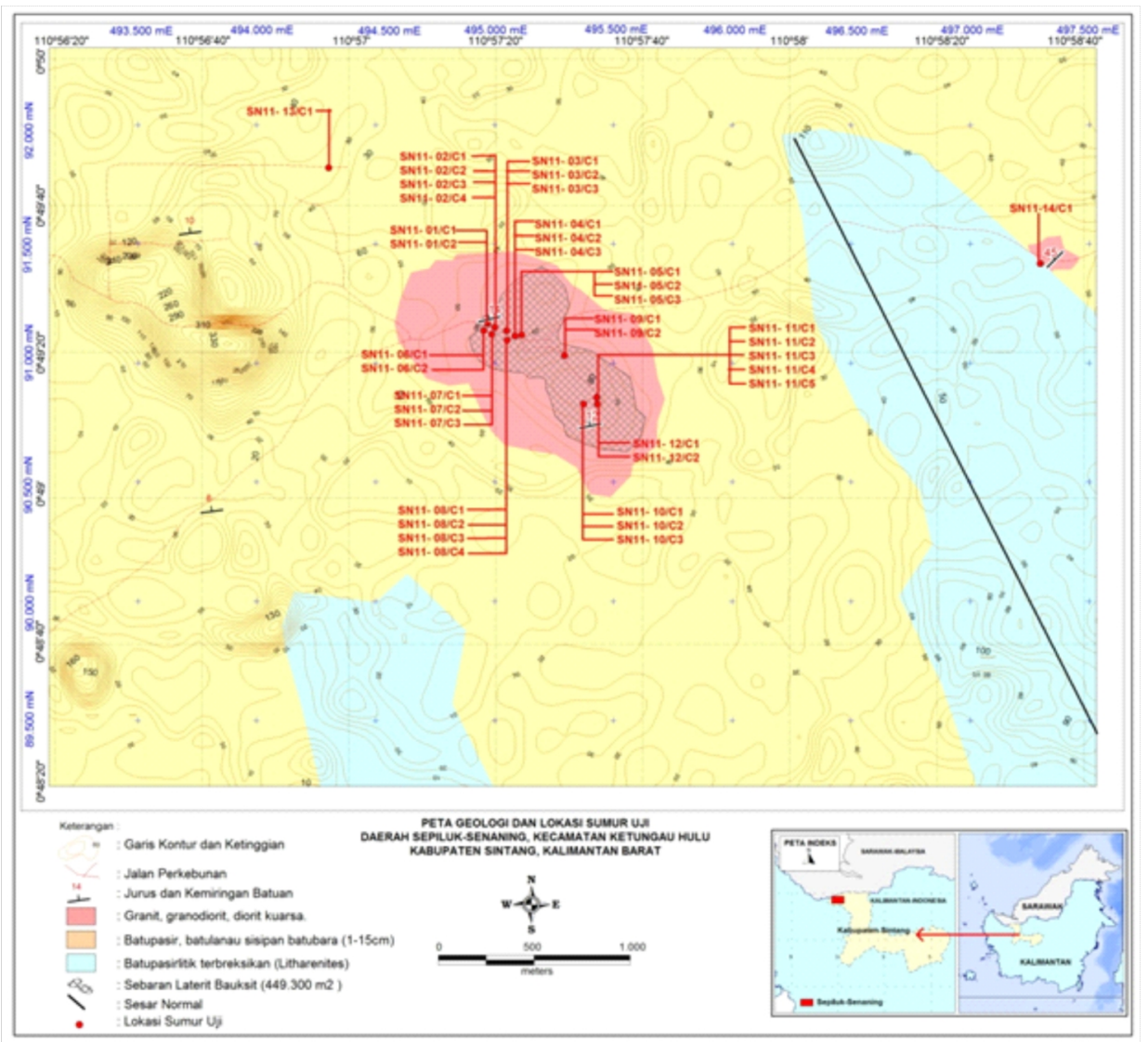

Gambar 3. Peta Geologi daerah Sepiluk-Senaning, Sintang

\section{METODOLOGI}

Metode penyelidikan untuk mengetahui ketebalan bauksit laterit adalah sumur uji yang merupakan suatu metode pengambilan conto bauksit laterit yang berada di bawah permukaan, dengan cara channel/paritan pada dinding sumur uji (Anonim, 1994) sekaligus melihat secara megaskopis susunan litologi atau perubahan warna tanah/batuan sampai pada kedalaman tertentu. Ukuran sumur uji yang biasa digunakan adalah minimal $1 \mathrm{~m} \mathrm{x}$ $1 \mathrm{~m}$ dan penggalian dihentikan jika mencapai lempung (kong), batuan keras dan air tanah. Sketsa cara pengambilan conto bauksit ditampilkan dalam Gambar 4 .

Penggalian sumur uji di daerah penyelidikan dilakukan pada jarak spasi antara $50 \mathrm{~m}$ sampai $100 \mathrm{~m}$. Penentuan lokasi titik sumur uji di lakukan dengan GPS (Global Positioning System).

Metode pengambilan conto bauksit laterit pada sumur uji adalah sebagai berikut

1. Menentukan kedalaman sumur uji.

2. Menentukan batas antara lapisan batuan dengan bauksit laterit.

3. Menentukan ketebalan lapisan bauksit laterit.

4. Menentukan batas antara lapisan penutup (overburden) dengan bauksit laterit.

5. Melakukan pemerian bauksit laterit di lapangan.

6. Pengambilan conto dilakukan pada dinding yang paling panjang, dengan labeling pada pita dan plastik conto, agar memudahkan dalam pengolahan data dan saat analisis laboratorium.

Pengambilan conto dan pemerian pada lubang sumur uji yang mengandung bauksit dilakukan dengan channel sampling dengan lebar $10 \mathrm{~cm}$, menjorok ke dinding sepanjang $10 \mathrm{~cm}$ dengan interval kedalaman $1 \mathrm{~m}$. Dengan demikian jumlah conto yang diambil tergantung pada tebal bauksit laterit.

Pengambilan conto dilakukan juga pada tebing bukaan dengan memperhatikan jarak sumur uji sebelumnya. 


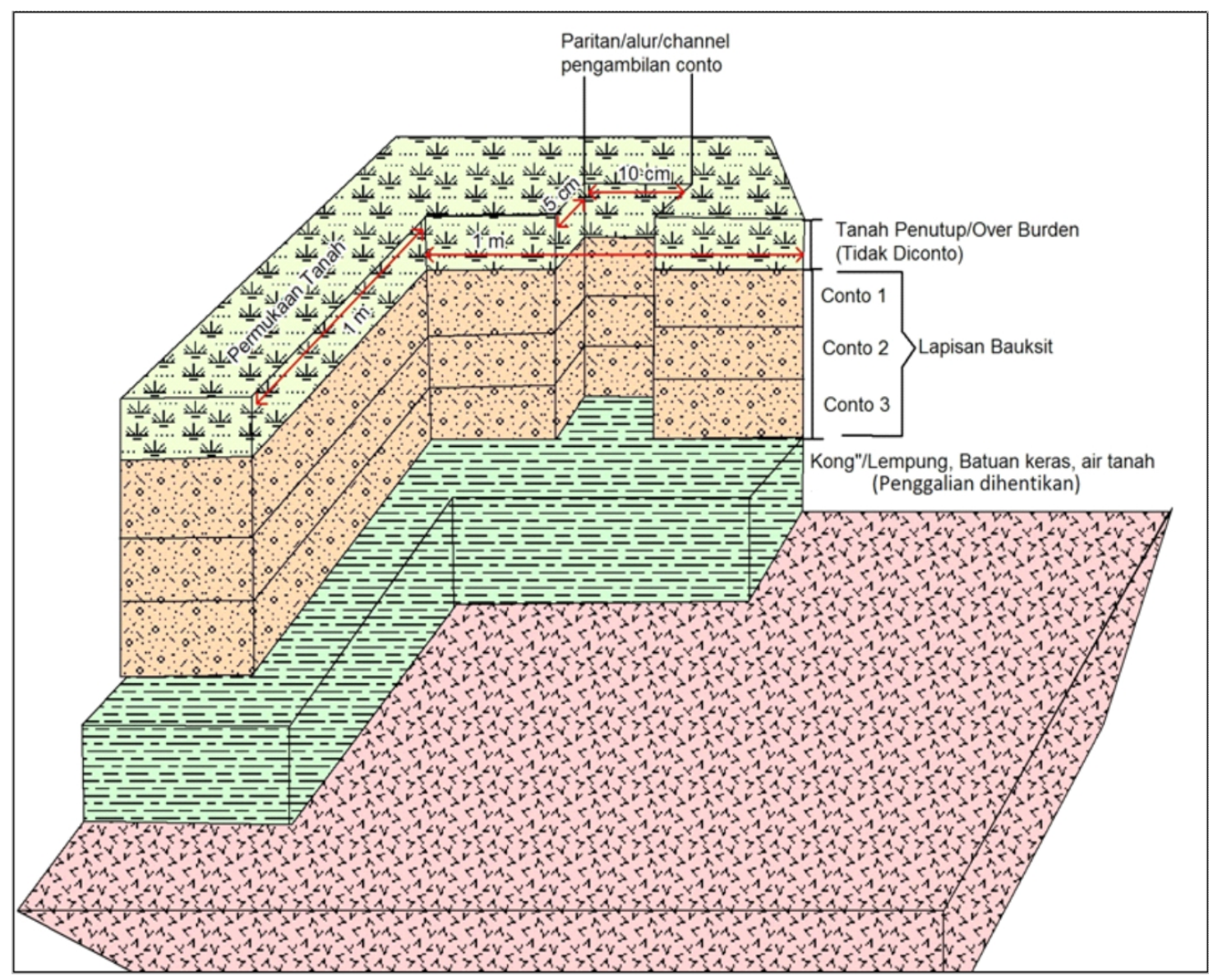

Gambar 4. Sketsa cara pengambilan conto bauksit dengan sumur uji (modifikasi dari Anonim,1994 dan Anonim, 2000)

\section{Preparasi Conto}

Setelah pengambilan conto di lokasi penyelidikan, selanjutnya conto di bawa ke basecamp untuk dilakukan preparasi conto sebagai berikut (Gambar 5):

1. Conto dari lokasi ditimbang untuk mengetahui berat kotor.

2. Conto kotor dicuci dengan ayakan berukuran $1 \mathrm{~cm}$ dan $5 \mathrm{~mm}$ secara manual hingga bersih, agar butiran yang lolos (matriks) dan bahan pengotornya hilang.

3. Dilakukan pengeringan dengan di angin-anginkan sampai 24 jam (Gambar 6A).

4. Conto kering yang bersih ditimbang, untuk mengetahui berat bersih.

5. Menghitung faktor konkresi (CF=berat bersih/berat kotor $\mathrm{x}$
100\%) (Anonim,1994).

6. Conto dihaluskan hingga ukuran < $0,5 \mathrm{~cm}$ (Gambar 6 B)

7. Conto di mixing dan quatering (pencampuran 4 bagian) sehingga fraksi conto menjadi homogen (Gambar 6 C)

8. Conto diambil $1 \mathrm{Kg}, 0,5 \mathrm{Kg}$ dianalisis di laboratorium dan sisanya menjadi duplikat (Gambar 6D)

Conto yang sudah dipreparasi tersebut, selanjutnya dikirim ke laboratorium untuk dilakukan analisis senyawa-senyawa $\mathrm{Al}_{2} \mathrm{O}_{3}$, $\mathrm{Fe}_{2} \mathrm{O}_{3}, \mathrm{SiO}_{2}, \mathrm{TiO}_{2}, \mathrm{CaO}, \mathrm{MgO}$ dan HD. Selain itu untuk beberapa conto yang didapat di lokasi penyelidikan juga dilakukan analisis petrografi, mineragrafi dan berat jenis. 


\section{MAKALAH ILMIAH}

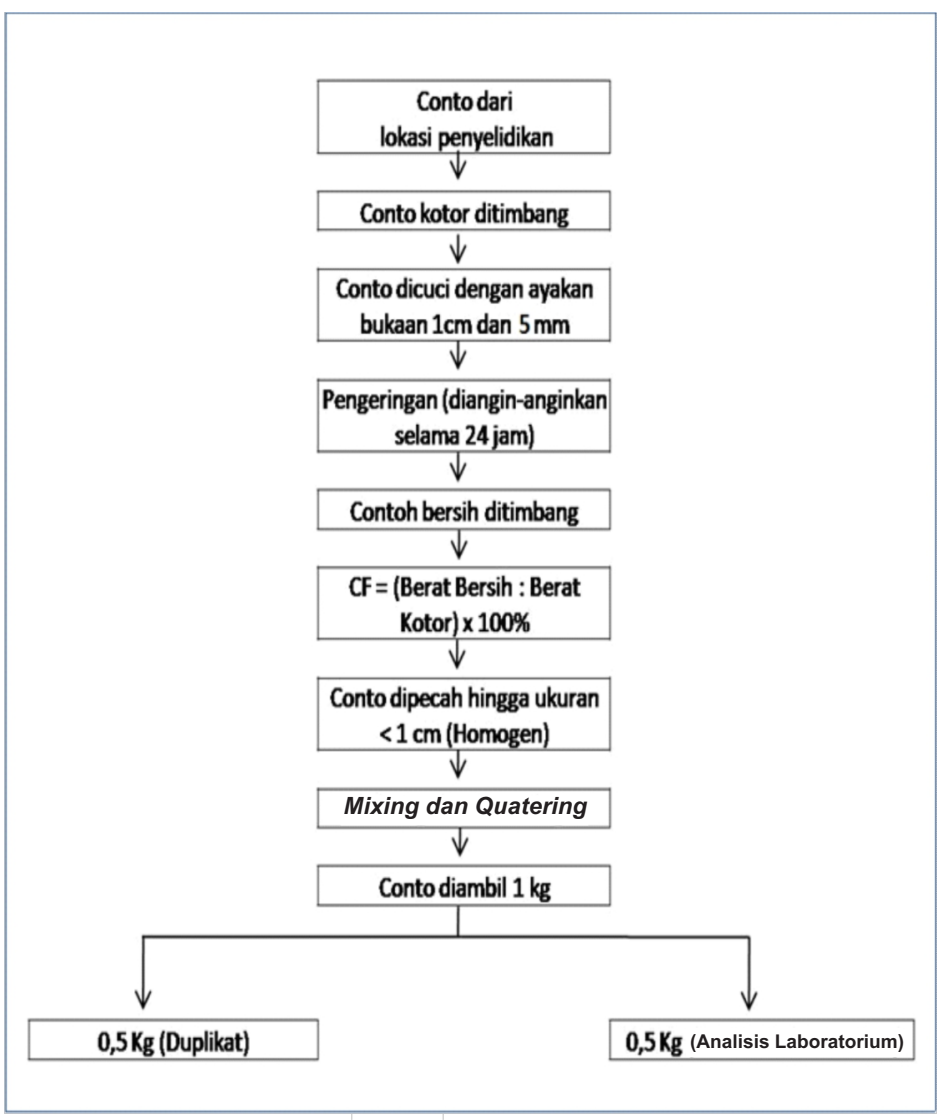

Gambar 4. Sketsa cara pengambilan conto bauksit dengan sumur uji (modifikasi dari Anonim,1994 dan Anonim, 2000)

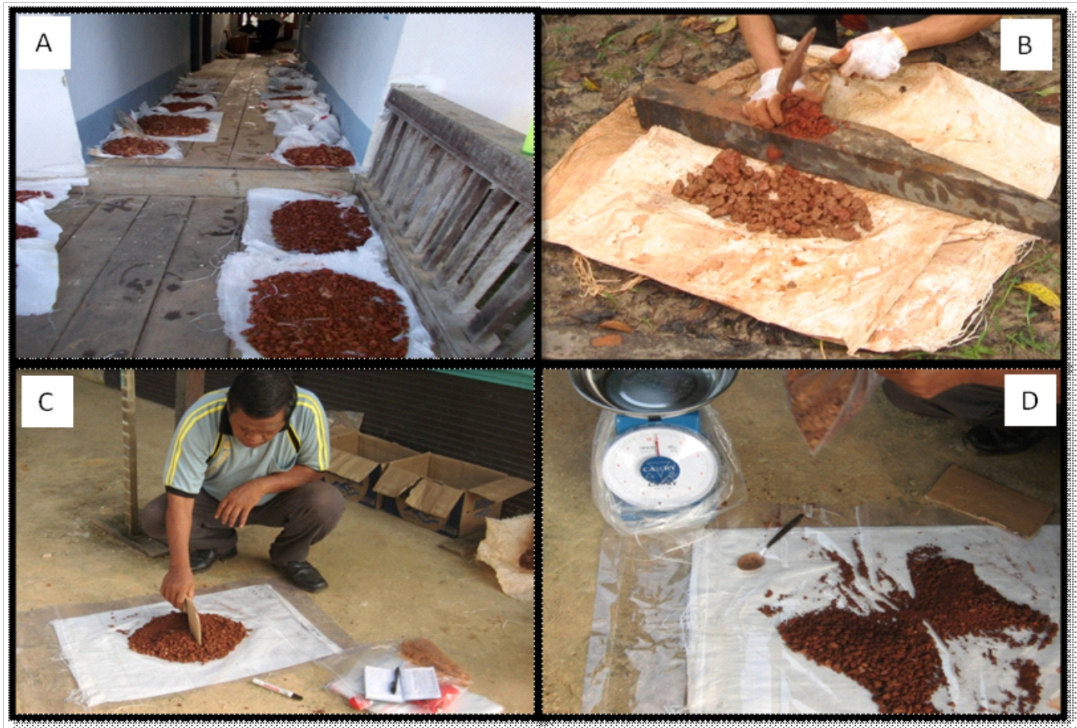

Gambar 6. A) Pengeringan conto bersih, selama 24 jam

B) Penghalusan conto hingga ukuran $<1 \mathrm{~cm}$

C) Quatering conto agar menjadi homogen

D) Conto diambil $1 \mathrm{~kg}$, dikirim untuk analisis laboratorium seberat $0,5 \mathrm{Kg}$ 


\section{HASIL DAN PEMBAHASAN}

Darianalisis mineragrafi conto di daerah penyelidikan teridentifikasi sebagian besar berupa mineral hematit dan oksida besi yang tersebar dalam batuan (Gambar 7A). Dari pemeriksaan mineral bijih sayatan poles batuan di bawah mikroskop cahaya pantul, mineral logam yang teridentifikasi adalah hematit, berbutir halus hingga $+0,1 \mathrm{~mm}$, dengan bentuk subhedral hingga anhedral yang telah terubah menjadi hydrous iron oxide (Gambar 7B). Sedangkan dari analisis petrografi terindentifikasi mineral gibsit dan cliachit yang umumnya berupa nodul dikelilingi oleh mineral opak. Gibsit terdapat mengisi rongga dengan bentuk anhedral sedangkan cliachit kemungkinan sudah bercampur bersama oksida besi terlihat mengelilingi mineral gibsit. Kehadiran felspar berukuran 0,25 mm dengan bentuk butir anhedral-subhedral telah mengalami proses laterisasi dan tersebar menjadi mineral gibsit (Gambar 8).

Kehadiran mineral gibsit sangat umum merupakan sumber utama terbentuknya bauksit laterit di daerah penyelidikan. Variasi iklim musiman juga dianggap penting dalam pembentukan bauksit. Musim panas dan dingin menyebabkan fluktuasi pada muka air tanah, yang membuat terjadinya pelarutan dan transfer massa. Variasi pada profil bauksit sebagai transformasi dari gibsit yang terdehidrasi menjadi versi yang terhidrasi secara relatif menghasilkan boehemit atau diaspor $(\alpha-\mathrm{AlO}(\mathrm{OH}))$.

Batupasir litik terbreksikan juga terindentifikasi terisi oleh mineral-mineral lempung dan butiran halus kuarsa $(30 \%)$, urat epidot kuarsa yang saling berpotongan pada zona rekahan, tersusun oleh mineral kuarsa, plagioklas, muskovit, klorit, mineral opak didalam masa dasar klorit (Gambar 9). Disamping itu, hasil diagram statistik pengklasifikasian batuan gunungapi (Winchester and Floyd, 1977) $\mathrm{TiO}_{2}$ terhadap $\mathrm{SiO}_{2}$ juga terindentifikasi bahwa pelapukan dalam pembentukan bauksit laterit di daerah penyelidikan berasal dari batuan beku gunungapi fonolit yang kaya felspar dan gibsit (Gambar 10). Menurut Casimiro dan d'Avila, (1975) bauksit laterit yang terbentuk dari fonolit mempunyai kadar aluminium yang tinggi dengan gibsit sebagai mineral utama.

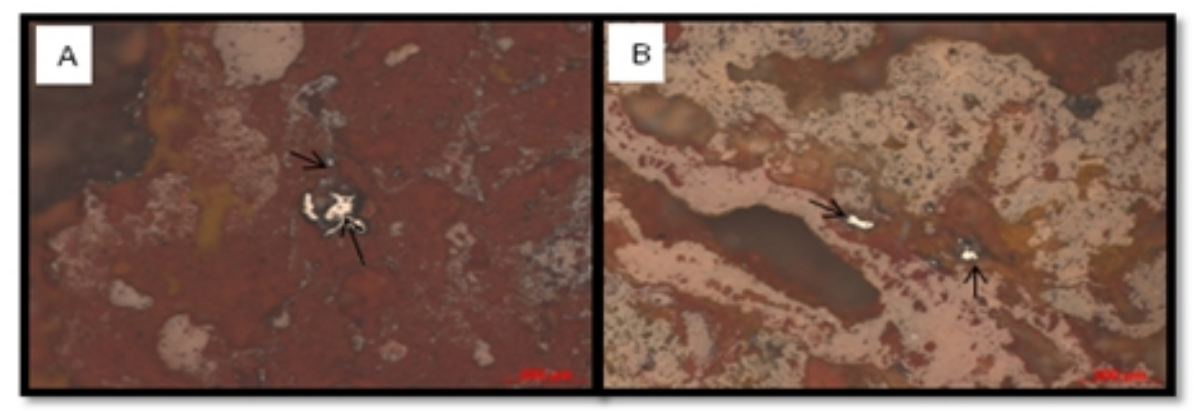

Gambar 7. : A dan B Fotomi krograf sayatan poles hematit dengan bentuk subhedral hingga anhedral yang nampak tersebar dalam batuan.

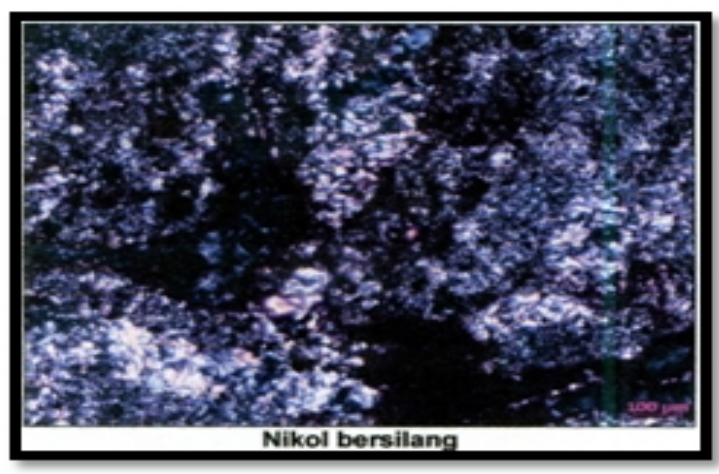

Gambar 8. Sayatan tipis laterisasi felspar menjadi cliachit dan gibsit 


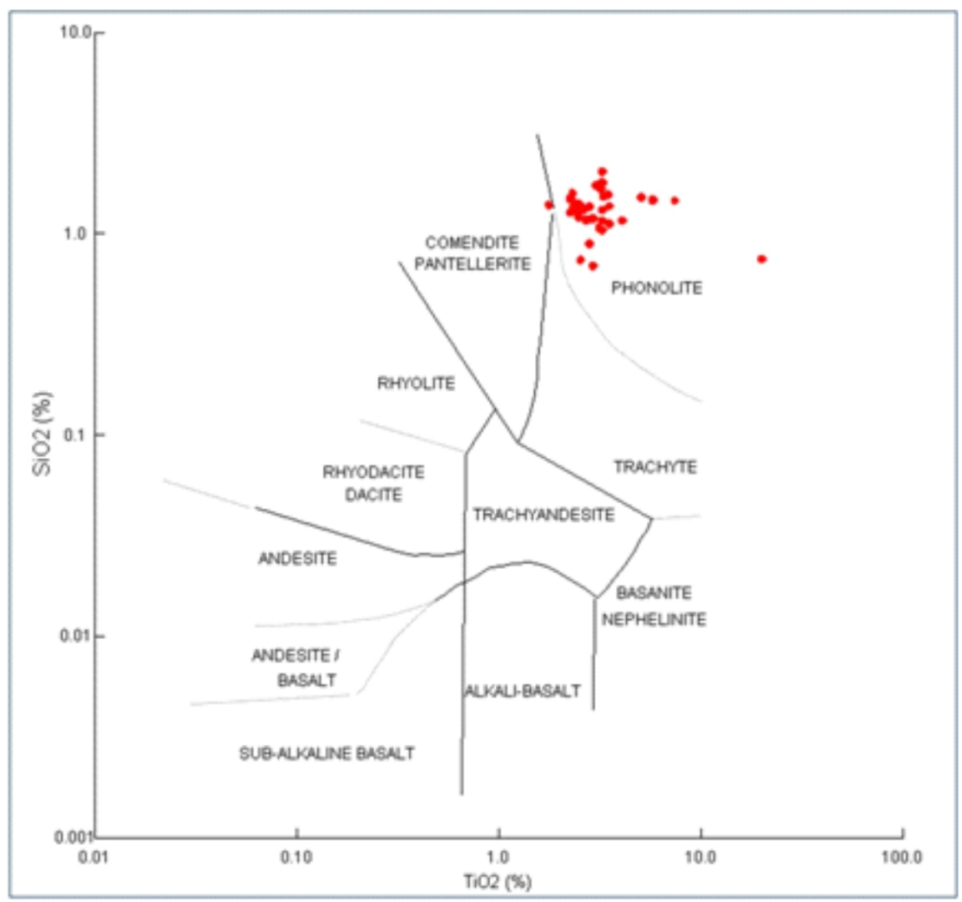

Gambar 10. Diagram klasifikasi batuan gunungapi $\mathrm{TiO}_{2}$ versus $\mathrm{SiO}_{2}$ (modifikasi dari Winchester and Floyd, 1977)

Tabel 1. Nilai statistik unsur tanah laterit daerah Sepiluk-Senaning

\begin{tabular}{|c|c|c|c|c|c|c|}
\hline Kimia Unsur & $\begin{array}{c}\text { Jmlh } \\
\text { Analisis }\end{array}$ & $\begin{array}{c}\text { Mean } \\
(\%)\end{array}$ & $\begin{array}{c}\text { Median } \\
(\%)\end{array}$ & $\begin{array}{c}\text { Minimum } \\
(\%)\end{array}$ & $\begin{array}{c}\text { Maximum } \\
(\%)\end{array}$ & $\begin{array}{c}\text { Std. Deviation } \\
(\%)\end{array}$ \\
\hline $\mathrm{SiO}_{2}$ & 39 & 3,60 & 2,93 & 1,77 & 20,15 & 2,92 \\
\hline $\mathrm{Al}_{2} \mathrm{O}_{3}$ & 39 & 52,64 & 53,52 & 17,90 & 54,99 & 5,78 \\
\hline $\mathrm{Fe}_{2} \mathrm{O}_{3}$ & 39 & 9,83 & 9,34 & 5,44 & 24,35 & 2,88 \\
\hline $\mathrm{CaO}$ & 39 & 0,44 & 0,33 & 0,04 & 1,66 & 0,36 \\
\hline $\mathrm{MgO}$ & 39 & 0,28 & 0,28 & 0,02 & 0,48 & 0,10 \\
\hline $\mathrm{TiO}_{2}$ & 39 & 1,34 & 1,36 & 0,69 & 2,03 & 0,29 \\
\hline $\mathrm{H}_{2} \mathrm{O}$ & 39 & 0,51 & 0,49 & 0,21 & 1,67 & 0,211 \\
\hline $\mathrm{HD}$ & 39 & 28,71 & 29,28 & 10,74 & 30,32 & 3,057 \\
\hline
\end{tabular}

Analisis kimia unsur terhadap 39 conto tanah membuktikan bahwa semua conto di daerah ini merupakan tanah laterit dengan rata-rata kandungan $52,64 \% \mathrm{Al}_{2} \mathrm{O}_{3} ; 3,60 \%$ $\mathrm{SiO}_{2} ; 9,83 \% \mathrm{Fe}_{2} \mathrm{O}_{3}$ dan $1,34 \% \mathrm{TiO}_{2}$ (Tabel 1). Pada diagram ternary terlihat bahwa bauksit laterit terdistribusi kearah dengan kecenderungan $\mathrm{Al}_{2} \mathrm{O}_{3}$ tinggi(Gambar 11).

Hasil sumur uji menunjukkan adanya lapisan penutup bervariasi dari $0,5 \mathrm{~m}-3 \mathrm{~m}$. Di bawah lapisan penutup terlihat nodulnodul atau konkresi bauksit dengan ketebalan bervariasi dari $1 \mathrm{~m}-5 \mathrm{~m}$. Di bawah lapisan bauksit pada umumnya dijumpai zona peralihan sebelum mencapai batuan segar dengan ketebalan rata-rata bauksit laterit mencapai 2,6 $\mathrm{m}$ dan rata-rata ketebalan tanah penutup 1,74 $\mathrm{m}$ (Tabel 2).

Perbandingan berat bauksit tercuci kering diudara dengan berat bauksit kotor (faktor konkresi) ditampilkan dalam Tabel 3, dengan rata-rata faktor konkresi bauksit $0,58 \%$ dan berat jenis $1,22 \mathrm{gr} / \mathrm{cm}_{3}$.

Keberadaan bauksit laterit di daerah penyelidikan terdapat pada kemiringan lereng $10^{\circ}$ s.d $14^{\circ}$ (Gambar 12). Gambaran penyebaran vertikal bauksit laterit di daerah penyelidikan dapat dijelaskan dari korelasi 


\section{MAKALAH ILMIAH}

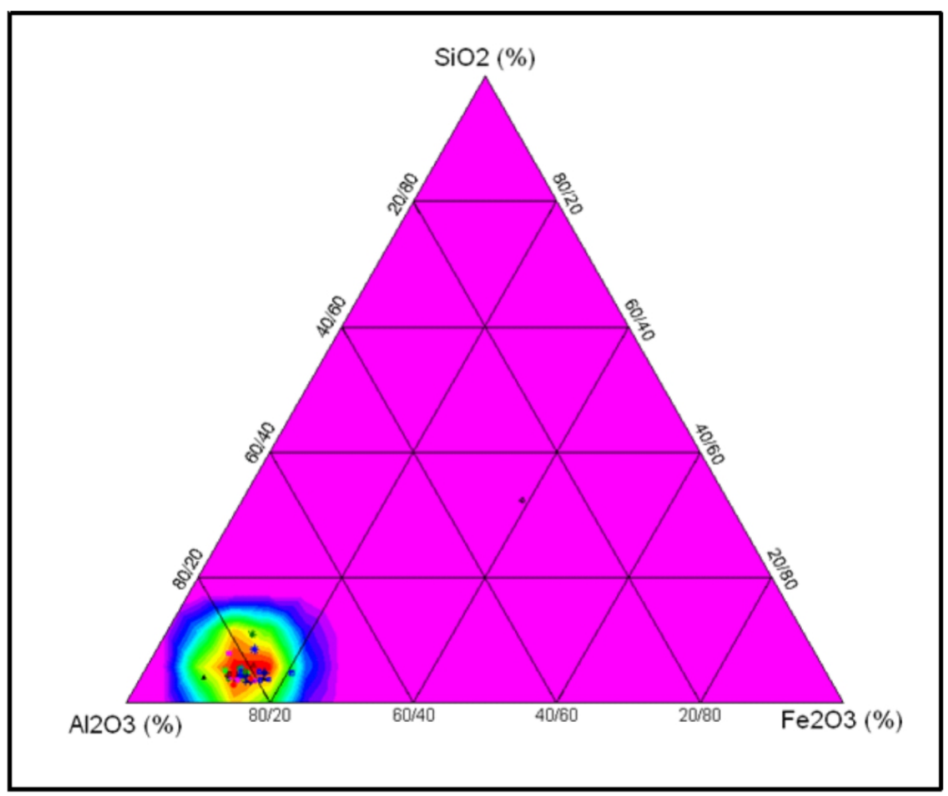

Gambar 11. Diagram Ternary distribusi $\mathrm{Al}_{2} \mathrm{O}_{3}-\mathrm{Fe}_{2} \mathrm{O}_{3}-\mathrm{SiO}_{2}$ dari analisis kimia unsur (modifikasi dari Winchester and Floyd, 1977)

Tabel 2. Nilai statistik ketebalan lapisan bauksit dan tanah penutup

\begin{tabular}{|lc|c|c|c|c|}
\hline & $\begin{array}{c}\text { Jumlah } \\
\text { Test_Pit }\end{array}$ & $\begin{array}{c}\text { Minimum } \\
(\mathrm{m})\end{array}$ & $\begin{array}{c}\text { Maximum } \\
(\mathrm{m})\end{array}$ & $\begin{array}{c}\text { Mean } \\
(\mathrm{m})\end{array}$ & $\begin{array}{c}\text { Std. Deviation } \\
(\mathrm{m})\end{array}$ \\
\hline Tanah Penutup & 15 & 0,50 & 3,00 & 1,74 & 0,73 \\
\hline Bauksit & 15 & 1,00 & 5,00 & 2,60 & 1,18 \\
\hline
\end{tabular}

Tabel 3.Nilai statistik hasil faktor konkresi conto bauksitdi daerah Sepiluk-Senaning

\begin{tabular}{|c|cc|c|}
\hline & $\begin{array}{c}\text { BeratKotor } \\
(\mathrm{Kg})\end{array}$ & $\begin{array}{c}\text { BeratBersih } \\
(\mathrm{Kg})\end{array}$ & $\begin{array}{c}\text { Faktor Konkresi } \\
(\%)\end{array}$ \\
\hline Jumlah Conto & 39 & 39 & 0 \\
\hline Data Error & 0 & 0 & 0,58 \\
\hline Mean & 3,95 & 2,25 & 0,12 \\
\hline Std. Deviation & 0,62 & 0,57 & 0,06 \\
\hline Minimum & 2,92 & 0,27 & 0,72 \\
\hline Maximum & 5,75 & 3,35 & \\
\hline
\end{tabular}

antara penampang sumur uji berarah tenggara-baratlaut yang mengkorelasikan sumur uji SN11-01 sampai dengan SN11-05 (Gambar 13). Hasil korelasi tersebut memperlihatkan bauksit laterit menipis ke arah tenggara - baratlaut. Pada sumur uji SN11-06 s.d. SN11-12 juga terlihat penyebaran bauksit laterit menipis ke arah tenggara - baratlaut dan laterit lempung semakin menebal (Gambar 14).

Sumber bauksit laterit di daerah penyelidikan adalah batuan gunungapi PraTersier dengan jenis fonolit. Batuan inibersifat asam-menengah yang kaya kandungan unsur aluminium dengan mineral gibsit, felspar dan cliachit, yang mudah larut kemudian mengalami proses laterisasi yaitu proses perubahan suhu secara ekstrim dan terus menerus sehingga batuan mengalami pelapukan. Bauksit laterit pada hasil sumur uji umumnya berwarna coklat kekuningan hingga coklat kemerahan, kompak, rapuh- 


\section{MAKALAH ILMIAH}

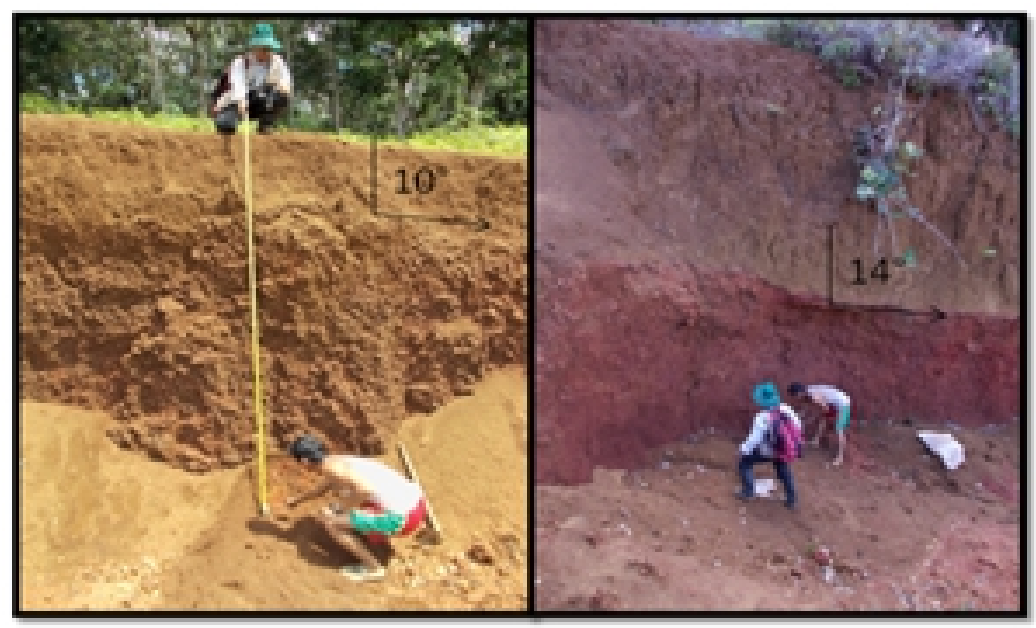

Gambar 12. Kemiringan Bauksit Laterit di daerah penyelidikan

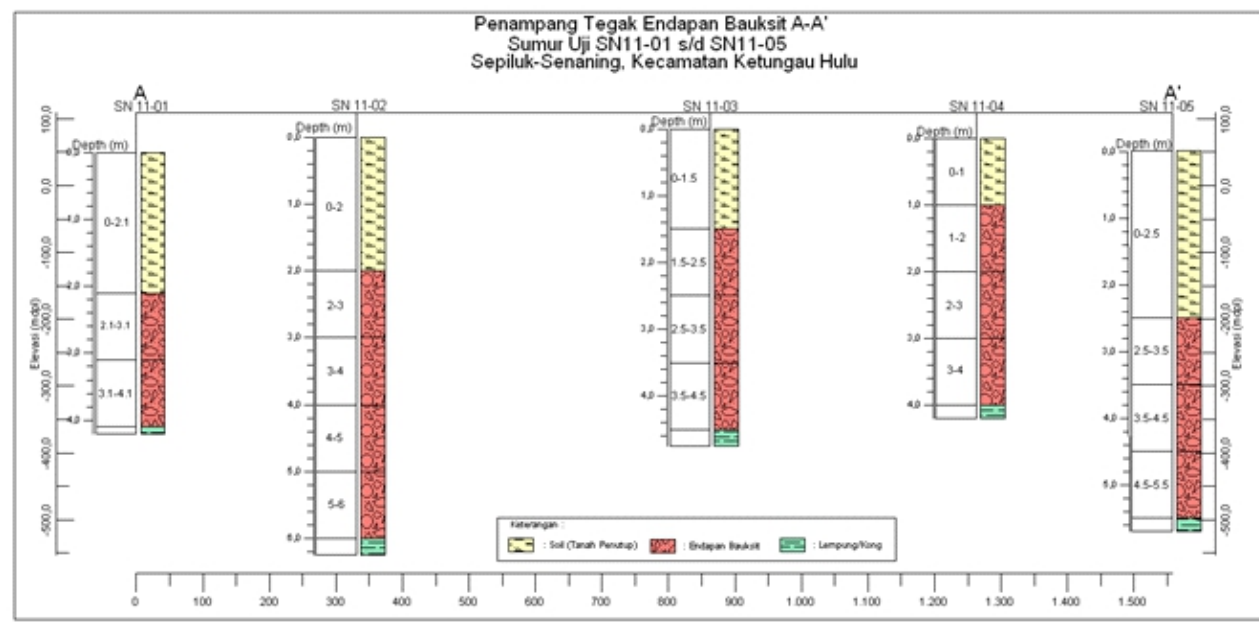

Gambar 13. Penampang Tegak Bauksit Laterit Sumur Uji SN 11-01 s.d. SN11-05

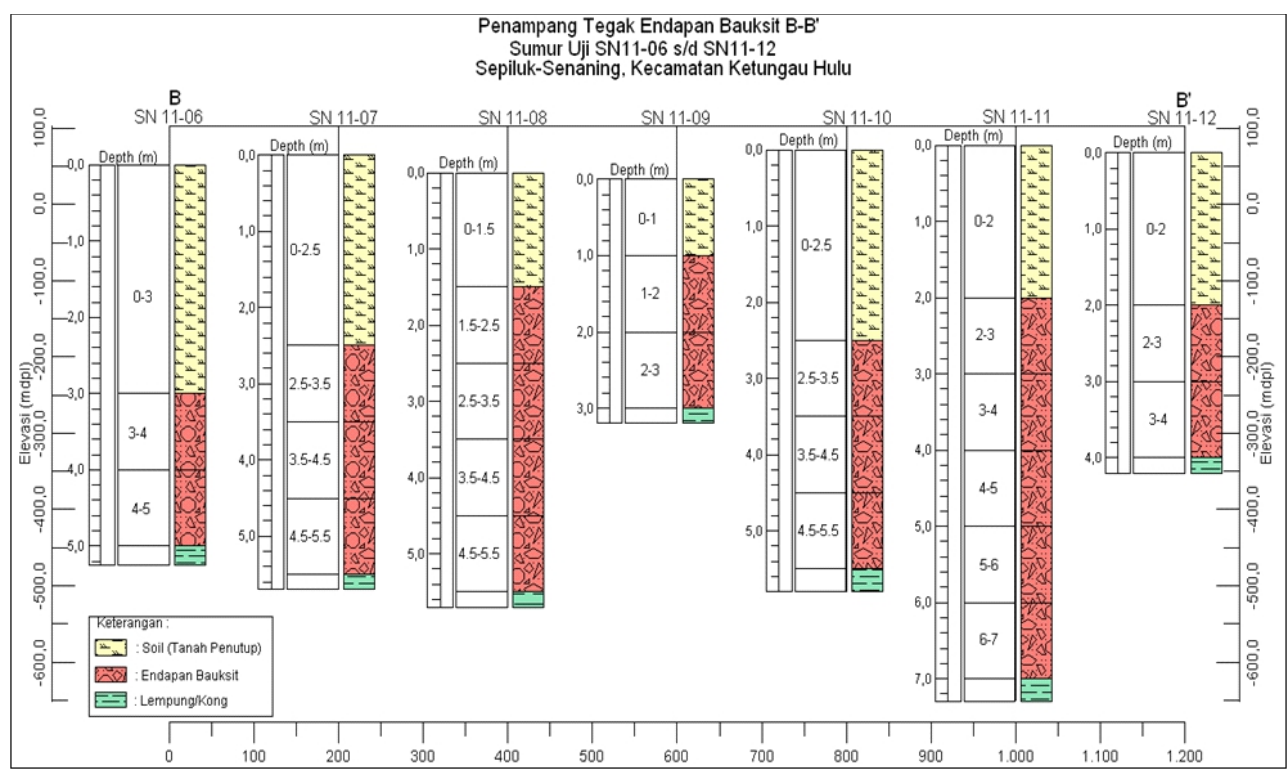

Gambar 14. Penampang Tegak Bauksit Laterit Sumur Uji SN 11-06 s.d. SN11-12 


\section{MAKALAH ILMIAH}

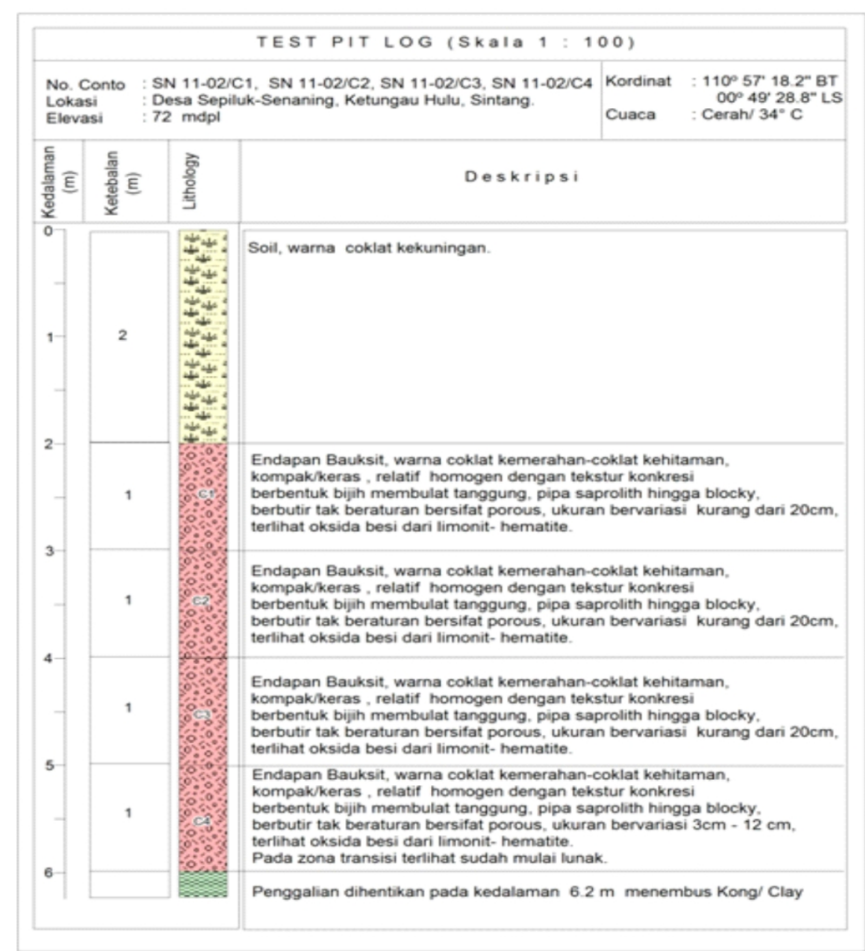

Gambar 15. Deskripsi Sumur Uji SN11-02

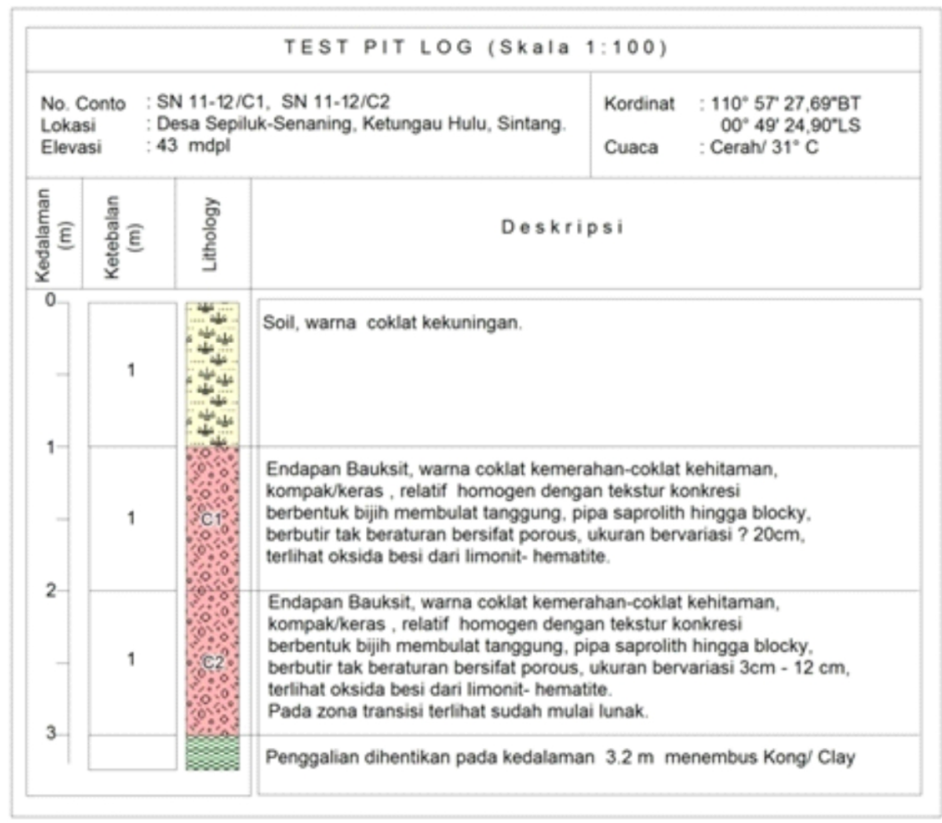

Gambar 16. Deskripsi Sumur Uji SN11-12 
keras dengan bentuk butir membulat tanggung, relatif homogen membentuk pipa saprolit hingga blocky. Deskripsi sumur uji SN11-02 dan SN11-12 ditampilkan dalam Gambar 15 dan Gambar 16 dengan kedalaman sumur uji maksimal mencapai $7,20 \mathrm{~m}$.

\section{KESIMPULAN}

Keberadaan cebakan bauksit di daerah penyelidikan terbentuk pada kemiringan lereng $10^{\circ} \mathrm{s} . \mathrm{d} .14^{\circ}$, mengansumsikan bahwa semakin kecil sudut kemiringan lereng, maka semakin luas akumulasi bauksit laterit jika dibandingkan dengan sudut kemiringan yang besar. Cebakan bauksit di daerah penyelidikan terbentuk pada batuan yang banyak memiliki kandungan unsur aluminium dengan mineral gibsit, felspar dan cliachit, yang mengalami proses laterisasi di daerah tropis. Bauksit laterit di daerah ini memiliki komposisi utama gibsit, felspar dan cliachit pada batuan beku fonolit. Sebaran bauksit ini hanya setempat-setempat yang menunjukkan bahwa proses terjadinya dipengaruhi oleh erosi yang intensif. Faktor topografi/kemiringan juga sangat berperan dalam terbentuknya akumulasi bauksit laterit.

\section{UCAPAN TERIMAKASIH}

Penulis mengucapkan terima kasih kepada teman-teman yang telah memberikan masukan sehingga dapat diterbitkan dalam Buletin Sumber Daya Geologi.

\section{DAFTAR PUSTAKA}

Anonim 2011, Eksplorasi Umum Bauksit di Kabupaten Sintang, Provinsi Kalimantan Barat, Pusat Sumber Daya Geologi.

Anonim 2007, Inventarisasi Dan Penyelidikan Mineral Dan Batubara Daerah Perbatasan Sintang, Provinsi Kalimantan Barat Dengan Malaysia, Pusat Sumber Daya Geologi.

Anonim 2000, Tata Cara Pembuatan Sumur Uji Secara Manual (SNI 03-6376-2000), Badan Standarisasi Nasional.

Anonim 1999, Penentuan Faktor Konkresi Bijih Bauksit (SNI 13-6179-1999), Badan Standarisasi Nasional.

Anonim 1994, Laporan Eksplorasi ANTAM, Daerah KP DU. 1144/KALBAR, Kabupaten Sanggau, Kalimantan Barat, PT. ANTAM.

Anonim 1974,On The Establishment of Bauxite Mining Alumina Refining and Aluminum Smelting Enterprises in Indonesia, Volume I \& II, PT. Alcoa Mineral of Indonesia.

Casimiro and d'Avila, 1975, Laterite Type Bauxite and Clayed Bauxite in Municipio de Lajes, Santa Catarina.

Eggleton, R. A. (ed.) 2001,The Regolith Glossary: surficial geology, soils and landscapes. CRC LEME, Wembley.

Heryanto. R, Harahap. B.H, Sanyoto.P, Williams.P.R, Pieters.P.E,1993; Geologi Lembar Sintang, Kalimantan, Skala $1: 250.000$, Puslitbang Geologi, Bandung.

Winchester, J.A., Floyd, P.A., 1977. Geochemical discrimination of different magma series and their differentiation products using immobile elements. Chemical Geology 20, page 325-344.

Diterima tanggal 10 Maretl 2012

Revisi tanggal 28 April 2012 